\title{
CONTRIBUTION OF SOME PHYSICAL CHARACTERISTICS TO UNIPEDAL NON-DOMINANT LOWER LIMB BALANCE AMONG FOOTBALLERS
}

original paper

( ) University School of Physical Education in Wroclaw

DOI: https://doi.org/10.5114/hm.2018.77328

\section{FRANCIS OLUWAFUNSO FASUYI, BABATUNDE OLUSOLA A. ADEGOKE}

Department of Physiotherapy, College of Medicine, University of Ibadan, Ibadan, Nigeria

\begin{abstract}
Purpose. The objective was to determine the correlations between age, body mass index, foot length, tibia length, and calf circumference - and unipedal non-dominant lower limb balance (UNLLB), on the basis of the contributions of each physical attribute to UNLLB performance among professional football players in a Nigerian National Football League club.

Methods. This descriptive correlational study involved 32 purposively recruited male professional football players who met the inclusion criteria. The participants' age was recorded along with height, weight, foot length, tibia length, and calf circumference, measured with standardized procedures, while their UNLLB was assessed with the use of a Wii Balance Board. The primary outcome measure was UNLLB, reflecting the centre of pressure parameters. The data were analysed with the Spearman rank order correlation; stepwise multiple linear regression analysis was used to explore the contributions of the selected variables to UNLLB at 0.05 alpha levels.
\end{abstract}

Results. All physical attributes except age were significantly correlated with UNLLB. The stepwise regression analysis showed limb length $\left(13.2 \%, \mathrm{p}=0.023, f^{2}=0.191\right)$, calf circumference $\left(22.3 \%, p=0.004, f^{2}=0.329\right)$, and weight $(11.5 \%, p=$ $\left.0.033, f^{2}=0.167\right)$ to be significant contributors to UNLLB with visual input allowed, while tibia length $(14.9 \%, p=0.017$, $\left.f^{2}=0.215\right)$ and foot length $\left(9.5 \%, p=0.048, f^{2}=0.142\right)$ were significant predictors with visual input denied.

Conclusions. Limb length, calf circumference, body weight, tibia length, and foot length are significant predictors of UNLLB among professional footballers.

Key words: lower extremity, physical examination, football, soccer

\section{Introduction}

In football, players must necessarily involve their motor skills and control their posture to perform tasks that include passing, shooting, dribbling, and controlling the balance and postural stability. This affects the success of movements, passes, and shots. Considerable muscle strength, coordination, and balance are required to perform these weight-bearing activities, since football is a game with numerous fast dynamic actions (such as quick turning and dribbles), and resultantly high injury incidence [1]. A fast cutting action leaves the stance leg in the position for high levels of torque and shear force, thereby increasing the risk of injury, especially in comparison with linear movements $[2,3]$.
Repeated impulsive contacts between the footballers' feet and the support surface combined with effects of vertical impact loading have been indicated as contributing to injuries in footballers [1, 4], especially when the stance leg is perceived to be more medial than it actually is, thereby resulting in greater propensity for injury. Balance and position sense are therefore principally vital to limiting this potential for injury [3]. The mandatory restructuring of the centre of gravity over a short and narrow base of support [5] during unipedal stance results in postural instability; this factor elicits postural control differences between the lower extremities and has been used to explain why contact and overuse injuries predominantly affect the dominant leg [6, 7].

Correspondence address: Francis O. Fasuyi, Physiotherapy Department, University of Medical Sciences, PMB 536, Ondo, Nigeria, e-mail: tfunsho@gmail.com

Received: April 19, 2018

Accepted for publication: June 27, 2018

Citation: Fasuyi FO, Adegoke BOA. Contribution of some physical characteristics to unipedal non-dominant lower limb balance among footballers. Hum Mov. 2018;19(4):71-78; doi: https://doi.org/10.5114/hm.2018.77328. 
F.O. Fasuyi, B.O.A. Adegoke, Physical characteristics and unipedal balance

Barone et al. [7] reported that footballers had better standing balance than sedentary subjects during unipedal stance. Balance is pivotal to injury prevention among football players, and the role of their physical attributes cannot be underestimated since some previous studies have emphasized their significance to overall stability $[8,9]$. It is generally believed that physical attributes are necessary to achieve success in different sports; hence, studies have been conducted to identify the required characteristics for successful participation in particular disciplines. Consequently, the contribution of anthropometric variables such as height, weight, the weight of fatless body mass, fat weight, somatotype, and body fat to successful sports performance has been investigated [10]. A number of neurophysiological and mechanical factors are known to affect balance; these include height, weight, body composition, base of support, distance of centre of mass from the ground, length and weight of each extremity, length of muscles' torque arm, and mass distribution in different body points [11].

Physical attributes influence the stability limits of an individual and can affect the motor strategies relating to balance control. Obese individuals require greater movement from the centre of gravity to remain in the orthostatic position. The sole high body mass can contribute towards decreasing balance and occurrences of falls in situations of instability [9]. Cote et al. [8] has therefore highlighted these attributes as important in balance measurements in order to avoid error in its analysis. Establishing the relationship between selected physical attributes of footballers and unipedal nondominant lower limb balance (UNLLB) and subsequently determining the relative contributions of these attributes to UNLLB will be valuable to post-injury rehabilitation. The objectives of this study were to explore the correlations between some physical variables and UNLLB, as well as the contribution of each to UNLLB among professional football players from a Nigerian National Football League club in Ibadan, Nigeria.

\section{Material and methods}

\section{Participants}

The total of 32 male professional football players (78\% right leg dominant and 22\% left leg dominant) comprising 14 defenders, 13 midfielders, and 5 attackers participated in this descriptive correlational study. Their mean age, weight, and height were $28.19 \pm$ 4.10 years (range, $20-37$ years), $71.31 \pm 7.45 \mathrm{~kg}$, and $1.76 \pm 0.07 \mathrm{~m}$, respectively. The participants were pur- posively recruited from the Shooting Stars Football Club, a club in the Nigerian Professional Football League (NPFL), during the 2015 season. Exclusion criteria were lower extremity injuries; vestibular disorder; lack of medical clearance for participation; ongoing treatment for inner ear, sinus, upper respiratory infection, or head cold; and cerebral concussion within the previous 3 months, as suggested by Plisky et al. [12].

The management and coaching crew of the club permitted the conduct of the study. The participants met the inclusion criteria of competing in the NPFL for at least 2 previous seasons and underwent no prior balance training program apart from their typical football training [13]. Their physical attributes were assessed with standardized procedures as described by the International Society for the Advancement of Kinanthropometry [14].

\section{Balance assessment}

UNLLB evaluation was achieved through stabilometric analysis with a Wii Balance Board (WBB). The device is a $45 \mathrm{~cm}$ by $26.5 \mathrm{~cm}$ platform that contains 4 transducers, used to wirelessly transmit vertical ground reaction forces and the resultant movement in the centre of pressure (COP) from under each corner as a user stands or moves on its surface $[15,16]$. It provides accurate measures of $\mathrm{COP}$, which is an approximation of the body's centre of mass (or balance point) projected directly onto the floor below. COP has been documented as an important metric for balance stability assessment given that it closely approximates body sway $[15,16]$.

This assessment followed the procedure described by Barone et al. [7], with the participants lightly dressed. Unipedal stance was determined on each participant's non-dominant lower limb, which was previously defined as the lower limb that the participant would not preferentially use to kick a ball [3]. Next, the subject was asked to stand barefoot on the WBB with arms along the body and remain motionless on the non-dominant leg while focusing on an eye level marker on the wall to maintain minimal movement of the head. The dominant leg was positioned so that the hip was slightly flexed and the knee flexed to $90^{\circ}$. Two visual test conditions (eyes open and eyes closed) of UNLLB were applied.

The data recording time was limited to 5 seconds of unipedal stance as suggested by Barone et al. [7] because it is a most appropriate description of the time lapse for which a footballer might be in the stance since they perform fast movement and play drills. Three successful trials were conducted for each test condition 
and the average score was recorded [17]. A rest period of 15 seconds was applied between the trials. The participants' weight distribution data from the 4 sensors (TL - top left, TR - top right, BR - bottom right, and BL - bottom left) of the WBB when standing on their non-dominant legs for both test conditions were interfaced via a Bluetooth technology to a computer and obtained with a LabChart Pro version 8.0.9 software powered by ADInstruments Pty Ltd, Australia. These weight distribution data filtered at $100 \mathrm{~Hz}$ were used to calculate the COP in both $x$ and $y$ directions with the use of the following formulae provided by Sgrò et al. [16]:

- medio-lateral displacement:

$$
\mathrm{COPx}=(\mathrm{L} / 2) * \frac{(\mathrm{TL}+\mathrm{BR})-(\mathrm{TL}+\mathrm{BL})}{(\mathrm{TR}+\mathrm{TL}+\mathrm{BR}+\mathrm{BL})}
$$

- antero-posterior displacement:

$$
\mathrm{COPy}=(\mathrm{W} / 2) * \frac{(\mathrm{TL}+\mathrm{TL})-(\mathrm{BR}+\mathrm{BL})}{(\mathrm{TR}+\mathrm{TL}+\mathrm{BR}+\mathrm{BL})}
$$

The participants' balance performance was then recorded as COP parameters that were calculated as mean $\mathrm{COP}$ velocity, antero-posterior COP velocity, and medio-lateral COP velocity. The mean $\mathrm{COP}$ velocity, indicating a subject's net muscular force variation, was determined as the COP swaypath per unit period of assessment. The antero-posterior COP velocity, demonstrating the tone of the posterior aspect of a participant's limb, was calculated as the anteroposterior displacement per unit period of assessment. The medio-lateral COP velocity, which is an indicator of the tone of the hip and ankle musculature, was established as the medio-lateral displacement per unit period of assessment.

\section{Measurement of the anthropometric parameters}

The footballers' age as at last birthday was documented. A flexible measuring tape was used to measure the non-dominant leg length, tibia length, foot length, and calf circumference as follows, with the procedures described by the National Health and Nutrition Examination Survey [18]:

- Limb length: The participants' lower limbs were passively straightened to keep the pelvis level in the supine position. The length of the non-dominant lower limb was then measured as the distance between the anterior superior iliac spine to the most distal portion of the medial malleolus and recorded to the nearest $0.1 \mathrm{~cm}$.
- Tibia length: With the participant in the supine position, tibia length was measured as the distance from the superior border of the medial tibia condyle to the inferior border of the medial malleolus of the non-dominant lower limb and recorded to the nearest $0.1 \mathrm{~cm}$.

- Foot length: With the participant in the supine position, foot length was measured as the maximum length between the most prominent posterior part of the heel and the tip of the second toe and recorded to the nearest $0.1 \mathrm{~cm}$.

- Calf circumference: It was measured as the circumference of the most bulky part of the calf musculature in a plane perpendicular to the long axis of the calf of the non-dominant leg and recorded to the nearest $0.1 \mathrm{~cm}$.

\section{Data analysis}

Bivariate associations between the physical attributes and UNLLB measures during both experimental situations were explored with the Spearman rank order correlation. Stepwise multiple regression modelling was used to determine the relative contributions of the physical attributes (age, weight, height, body mass index [BMI], limb length, tibia length, foot length, and calf circumference) that were significant in the bivariate correlation analysis. The alpha level was set at 0.05 and all statistical analyses were performed with the SPSS 16.0 evaluation software for Windows (SPSS Inc., Chicago, USA).

\section{Ethical approval}

The research related to human use has been complied with all the relevant national regulations and institutional policies, has followed the tenets of the Declaration of Helsinki, and has been approved by the University of Ibadan/University College Hospital (UI/UCH) Human Research Ethics Committee, Ibadan, Nigeria (registration number: NHREC/05/01/2008a).

\section{Informed consent}

Informed consent has been obtained from all individuals included in this study.

\section{Results}

The participants' physical attributes are presented in Table 1. Their BMI ranged from 17.7 to $26.3 \mathrm{~kg} / \mathrm{m}^{2}$. Overall, 26 (81\%) participants had normal weight (BMI, $\left.18.5-24.99 \mathrm{~kg} / \mathrm{m}^{2}\right)$, while $5(16 \%)$ were overweight and only 1 was underweight. This is in accordance with 


\section{HUMAN MOVEMENT}

F.O. Fasuyi, B.O.A. Adegoke, Physical characteristics and unipedal balance

Table 1. Physical attributes of participants

\begin{tabular}{lcc}
\hline Attributes & Range $(n=32)$ & $\mathrm{X} \pm S D(n=32)$ \\
\hline Age (years) & $20-37$ & $28.19 \pm 4.10$ \\
Weight $(\mathrm{kg})$ & $34-80$ & $71.31 \pm 7.45$ \\
Height $(\mathrm{m})$ & $1.57-1.93$ & $1.76 \pm 0.07$ \\
BMI $\left(\mathrm{kg} / \mathrm{m}^{2}\right)$ & $17.7-26.3$ & $23.05 \pm 2.09$ \\
Limb length $(\mathrm{cm})$ & $85-106$ & $97.98 \pm 4.88$ \\
Tibia length $(\mathrm{cm})$ & $40-51$ & $45.37 \pm 2.78$ \\
Foot length $(\mathrm{cm})$ & $24.0-31.5$ & $27.86 \pm 1.67$ \\
Calf circumference $(\mathrm{cm})$ & $30.7-40.0$ & $36.31 \pm 1.98$ \\
\hline
\end{tabular}

BMI - body mass index

Table 2. Relationships between physical attributes and unipedal non-dominant lower limb balance

\begin{tabular}{|c|c|c|c|c|c|c|c|c|c|c|c|c|}
\hline \multirow{3}{*}{ Physical attributes } & \multicolumn{6}{|c|}{ Eyes open balance test } & \multicolumn{6}{|c|}{ Eyes closed balance test } \\
\hline & \multicolumn{2}{|c|}{$\begin{array}{l}\text { COP mean } \\
\text { velocity } \\
(\mathrm{mm} / \mathrm{s})\end{array}$} & \multicolumn{2}{|c|}{$\begin{array}{l}\text { Antero- } \\
\text { posterior } \\
\text { velocity } \\
(\mathrm{mm} / \mathrm{s})\end{array}$} & \multicolumn{2}{|c|}{$\begin{array}{l}\text { Medio- } \\
\text { lateral } \\
\text { velocity } \\
(\mathrm{mm} / \mathrm{s})\end{array}$} & \multicolumn{2}{|c|}{$\begin{array}{l}\text { COP mean } \\
\text { velocity } \\
(\mathrm{mm} / \mathrm{s})\end{array}$} & \multicolumn{2}{|c|}{$\begin{array}{l}\text { Antero- } \\
\text { posterior } \\
\text { velocity } \\
(\mathrm{mm} / \mathrm{s})\end{array}$} & \multicolumn{2}{|c|}{$\begin{array}{c}\text { Medio- } \\
\text { lateral } \\
\text { velocity } \\
(\mathrm{mm} / \mathrm{s})\end{array}$} \\
\hline & $r$ & $p$ & $r$ & $p$ & $r$ & $p$ & $r$ & $p$ & $r$ & $p$ & $r$ & $p$ \\
\hline Age & -0.04 & 0.85 & 0.07 & 0.69 & -0.15 & 0.39 & -0.22 & 0.20 & 0.06 & 0.74 & -0.29 & 0.11 \\
\hline Weight (kg) & 0.10 & 0.58 & $-0.40^{*}$ & 0.02 & $0.41^{*}$ & 0.01 & 0.14 & 0.44 & 0.18 & 0.32 & 0.28 & 0.11 \\
\hline Height (m) & 0.26 & 0.14 & -0.06 & 0.71 & 0.25 & 0.16 & $0.43^{*}$ & 0.01 & 0.14 & 0.45 & $0.51^{*}$ & 0.00 \\
\hline $\operatorname{BMI}\left(\mathrm{kg} / \mathrm{m}^{2}\right)$ & -0.26 & 0.14 & $-0.49^{*}$ & 0.00 & 0.21 & 0.24 & -0.07 & 0.69 & 0.13 & 0.47 & -0.02 & 0.88 \\
\hline Limb length $(\mathrm{cm})$ & $0.40^{*}$ & 0.02 & 0.21 & 0.24 & 0.18 & 0.31 & $0.45^{*}$ & 0.01 & 0.13 & 0.46 & 0.30 & 0.08 \\
\hline Tibia length (cm) & 0.26 & 0.15 & -0.07 & 0.67 & 0.25 & 0.15 & $0.40^{*}$ & 0.02 & 0.20 & 0.25 & 0.34 & 0.06 \\
\hline Foot length $(\mathrm{cm})$ & -0.01 & 0.94 & $-0.44^{*}$ & 0.01 & $0.38^{*}$ & 0.02 & $0.37 *$ & 0.04 & 0.20 & 0.26 & $0.41^{*}$ & 0.01 \\
\hline Calf circumference $(\mathrm{cm})$ & -0.13 & 0.47 & $-0.57 *$ & 0.00 & 0.32 & 0.06 & 0.07 & 0.69 & 0.13 & 0.44 & 0.19 & 0.29 \\
\hline
\end{tabular}

$\mathrm{COP}$ - centre of pressure, BMI - body mass index

* statistically significant at $\alpha=0.05$

Table 3. Stepwise regression analysis

\begin{tabular}{|c|c|c|c|c|c|c|c|c|}
\hline Balance variables & $\begin{array}{l}\text { Physical } \\
\text { attributes } \\
\text { entered }\end{array}$ & $\begin{array}{l}\text { Physical } \\
\text { attributes } \\
\text { removed }\end{array}$ & $R^{2}$ & Adjusted $R^{2}$ & $F$ & $p$ & $\begin{array}{c}\text { Standardized } \\
\text { beta }\end{array}$ & $\begin{array}{l}\text { Cohen } \\
f^{2}\end{array}$ \\
\hline \multicolumn{9}{|l|}{ Eyes open } \\
\hline COP mean velocity $(\mathrm{mm} / \mathrm{s})$ & Limb length & & 0.160 & $0.132^{*}$ & 5.709 & 0.023 & 0.400 & 0.191 \\
\hline Antero-posterior velocity $(\mathrm{mm} / \mathrm{s})$ & $\begin{array}{c}\text { Calf } \\
\text { circumference }\end{array}$ & $\begin{array}{l}\text { Weight } \\
\text { BMI } \\
\text { Foot length }\end{array}$ & 0.248 & $0.223^{*}$ & 9.914 & 0.004 & -0.498 & 0.329 \\
\hline Medio-lateral velocity $(\mathrm{mm} / \mathrm{s})$ & Weight & Foot length & 0.143 & $0.115^{*}$ & 5.013 & 0.033 & 0.378 & 0.167 \\
\hline \multicolumn{9}{|l|}{ Eyes closed } \\
\hline $\mathrm{COP}$ mean velocity $(\mathrm{mm} / \mathrm{s})$ & Tibia length & $\begin{array}{l}\text { Height } \\
\text { Limb length } \\
\text { Foot length }\end{array}$ & 0.177 & $0.149^{*}$ & 6.435 & 0.017 & 0.420 & 0.215 \\
\hline Medio-lateral velocity $(\mathrm{mm} / \mathrm{s})$ & Foot length & Height & 0.124 & $0.095^{*}$ & 4.252 & 0.048 & 0.352 & 0.142 \\
\hline
\end{tabular}

COP - centre of pressure, BMI - body mass index

* statistically significant at $\alpha=0.05$ 
allowed (eyes open), while tibia length (14.9\%) and foot length $(9.5 \%)$ were significant contributors when visual input was denied (eyes closed).

\section{Discussion}

The primary objective of the study was to evaluate the relative contributions of some selected physical attributes to UNLLB among professional footballers. The results showed that body weight, limb length, and calf circumference measures contributed in $11.5 \%$, $13.2 \%$, and $22.3 \%$, respectively, to the variance in the eyes open UNLLB among the participants. In the eyes closed condition, tibia length and foot length contributed in $14.9 \%$ and $9.5 \%$, respectively, to the variance in the UNLLB. The study provides evidence that body size can influence UNLLB, which might have an impact on rehabilitation. To the best of our knowledge, the study appears to be the only one in which the contributions of physical attributes to UNLLB among professional players have been investigated.

Calf circumference provides a good index of the plantar flexor strength related to muscle mass and can be a significant factor to consider in the torque generated in the foot. In the stepwise regression analysis, calf circumference was found to contribute in $22.3 \%$ to UNLLB, which makes it the most important contributor among the attributes selected in the study. The muscles involved in foot stability are predominantly located in the calf and would be heavily influenced by the amount of fat. The significant correlation among calf circumference, tibia, and foot length, and their respective contribution to UNLLB, expose the significance of leg dimension to neuromuscular performance analysis of the non-dominant leg.

\section{Participants' physical attributes}

Age, an important physical attribute, was included among the predictive variables because of its expected importance in assessing postural balance. Several studies have demonstrated that dynamic balance is greatly related to age, with older people exhibiting decreased dynamic balance [19-21]. As we observed with the comparison of other physical attributes, there was no significant relationship between the participants' age and their UNLLB performance though the subjects were athletes aged below 40 years. Irrespective of age, long-term sport participation and training augment neurosensory pathways and stimulate cutaneous nerve receptors or mechanoreceptors in the muscles, ligaments, and joint capsules of the knee and ankle, as evidenced by improved balance and proprioception [13]. Age on its own may not result in significant changes in balance parameters, but may be a reflection of slight increase in plantar flexor torque amplitude and frequency of torque adjustment, possibly to compensate for the reduced tightness of the calf muscle tendon in the older population [20]. With increasing age, there is an expected increase of torque bursts produced by plantar flexors. However, this outcome may have been due to the relative short period of time for balance assessment applied in this study, which could have caused no/lower amplitude of plantar flexors torque to elicit a relationship. Age was not a significant contributor in this study of young adults, which is consistent with other studies [22, 23].

During the eyes-open balance, both weight and BMI had significant negative correlations with the anteroposterior velocity parameter of UNLLB. Indeed, BMI is closely dependent on weight; since, two different persons could be said to have the same body mass but different body compositions (more fat mass or more muscle, which is heavier). Therefore, the way to clarify this could be using dual-energy X-ray absorptiometry; however, this was not possible in this study as the facility was not available. This implies that as weight and $\mathrm{BMI}$ increased, the antero-posterior velocity was reduced, which means better stability. It is, however, not in consonance with Alonso et al. [23], who reported that with greater body mass there was a greater antero-posterior sway in the eyes-open balance performance among 20-40-year-old irregularly physically active male and female individuals. This difference in the result might be because professional football players follow a regular pattern of physical activities that may result in less antero-posterior velocity. More so, the race of this sample seems to differ from that involved in the study by Alonso et al., which can make a difference because body density and composition differ between races. BMI has been reported to present an inverse correlation with balance [21,24] and the outcome of this study has corroborated this submission. Greve et al. [24] suggested that a $20 \%$ increase in body weight reduced the ability to make adjustments in response to external perturbations in the orthostatic position, with a consequent increase in postural instability. Hue et al. [22] also found that body weight significantly contributed to about half the balance experienced at top speed.

Greve et al. [9] reported body weight as the main anthropometric factor that influenced variation in postural balance; they indicated that body weight in association with BMI explained $66 \%$ of the variation 
F.O. Fasuyi, B.O.A. Adegoke, Physical characteristics and unipedal balance

in overall stability, 59\% in antero-posterior stability, and $65 \%$ in medio-lateral stability indexes in young adults. It was also reported that greater postural adjustments were necessary to maintain an erect posture when there was a build-up of adipose tissue, which caused a reduction in balance and increased the frequency of injuries and falls [25]. However, as weight increases in footballers, there is a concomitant increase in the medio-lateral velocity in the eyes-open test situation, as demonstrated in the positive correlation between the two variables observed in this study. This is in line with the submission of Alonso et al. [23] that a greater body mass results in bigger mediolateral sway. It could be that with increased body weight, the ankle strategy becomes insufficient to maintain the COP within the base of support. This means that during unipedal stance, the body applies torque at the hips to quickly move the COP with the proximal hip and trunk muscle activation in order to maintain the body equilibrium when the ankle strategy becomes inadequate [26].

In the absence of visual input, there was a positive relationship between height and both COP mean velocity and medio-lateral velocity. Thus, the taller a footballer is, the greater the displacement of their COP from the centre of their base of support. These significant positive correlations between UNLLB parameters and height suggest that perturbation increases in tall footballers when only the somatosensory and vestibular systems are engaged in keeping the COP within the base of support. This has effect on the motor strategies employed to complete the task as information goes from the central nervous system to motor neural pathways to stimulate appropriate muscles. The outcome of this study may suggest that taller individuals recruit more of the pelvis and lower limb musculature in arresting perturbation and keeping the COP which is high up within the base of their support. In consonance with what is commonly reported in literature, we observed that increases in height, limb length, tibia length, and foot length worsen COP mean velocity [22, 23, 27]. Thus, a significant positive relationship between these lower extremity dimensions and COP mean velocity in the absence of visual system was observed in this study. However, during the eyes open balance activity, only limb length showed a significant positive relation with $\mathrm{COP}$ mean velocity. With greater foot length and calf circumference, a significant reduction in the antero-posterior COP velocity was noted.

Longer foot and bulky gastrocnemius muscles result in a better control in the antero-posterior direc- tion, as implied by the observed significant inverse relationship between non-dominant leg physical attributes and antero-posterior COP velocity. Thus, there was a better unipedal balance when the input of the visual system was not eliminated. The idea may be that an increase in the calf muscles circumference brings about more efficient ankle efficiency, which in turn translates to better balance. Greater foot length, however, resulted in a bigger medio-lateral displacement in both test situations and a significant increase in COP mean velocity during eyes closed situation. In view of the direct relationship between height and foot length, this result is not unexpected; height was reported by Alonso et al. [23] to increase the medio-lateral and sway velocities in both eyes open and closed situations.

Though others have analysed stance position with eyes closed, the decision to study stability among professional football players with eyes closed stems from the sensory reweighting theory, which holds that when vision is actively engaged to track activities in the external environment (e.g. the ball or an opponent's position), the central nervous system can shift reliance to more trustworthy sources of information to optimize balance [28]. This means that when eyes are engaged, a footballer is liable to rely more on proprioceptive information from particular parts of the body for balance control. For instance, ankle proprioception, which is one of the important components contributing to balance control in sport, becomes activated. The resultant postural control adjustments are made by movement strategies such as those related to ankle, hip, and stepping. The influence of the selected physical attributes on these strategies prompted the inclusion of the eyes closed test.

\section{Limitation and recommendations}

The findings from this study must be taken with some caution, a major drawback being the small sample size. However, the adjusted $R^{2}$ value rather than the $R^{2}$ value was calculated, as it was reported by Pallant [29] to provide a better estimation of the true population value. This study has, however, produced useful preliminary data on predictors of UNLLB among footballers. Future research should be longitudinal in design, involve a larger sample, consider other attributes that can possibly affect postural stability (such as foot structure), and use more sophisticated balance platforms. 


\section{Conclusions}

Limb length, calf circumference, body weight, tibia length, and foot length are significant determinants of UNLLB among football players. Lower extremity dimension measures have been shown to influence UNLLB.

\section{Acknowledgements}

The authors thank the participants of the study. The project was implemented as part of academic work in the university and no funding was received from any government or private organization.

\section{Disclosure statement}

No author has any financial interest or received any financial benefit from this research.

\section{Conflict of interest}

The authors state no conflict of interest.

\section{References}

1. Ogwumike OO, Tijani A. Balance performance of professional footballers with long-term lower limb musculoskeletal injury. Afr J Physiother Rehab Sci. 2011;3(1): 23-27; doi: 10.4314/ajprs.v3i1.5.

2. Hoff J, Helgerud J. Endurance and strength training for soccer players: physiological considerations. Sports Med. 2004;34(3):165-180; doi: 10.2165/00007256200434030-00003.

3. Fletcher IM, Long CS. The effects of kicking leg preference on balance ability in elite soccer players. J Athl Enhancement. 2013;2(3):3-6; doi: 10.4172/23249080.1000114.

4. Chu D, Held J. Objective assessment of the ACL-injured patient: weight bearing, steeping up/down and lunging. Neurocom Int. 1999;1:1-11.

5. Riemann BL, Myers JB, Lephart SM. Comparison of the ankle, knee, hip, and trunk corrective action shown during single-leg stance on firm, foam, and multiaxial surfaces. Arch Phys Med Rehabil. 2003;84(1):9095; doi: 10.1053/apmr.2003.50004.

6. Faude O, Junge A, Kindermann W, Dvorak J. Risk factors for injuries in elite female soccer players. Br J Sports Med. 2006;40(9):785-790; doi: 10.1136/bjsm. 2006.027540.

7. Barone R, Macaluso F, Traina M, Leonardi V, Farina F, Di Felice V. Soccer players have a better standing balance in nondominant one-legged stance. Open Access J Sports Med. 2010;2:1-6; doi: 10.2147/OAJSM.S12593.

8. Cote KP, Brunet ME, Gansneder BM, Shultz SJ. Effects of pronated and supinated foot postures on static and dynamic postural stability. J Athl Train. 2005; 40(1):41-46.
9. Greve JMD, Cŭg M, Dülgeroğlu D, Brech GC, Alonso AC. Relationship between anthropometric factors, gender, and balance under unstable conditions in young adults. Biomed Res Int. 2013;2013:850424; doi: 10.1155/ 2013/850424.

10. Hobbs ML. Dynamic balance and basketball education program on static balance skills of playing ability. MSc dissertation. San Marcos: Texas State University; 2008.

11. Tabrizi HB, Abbasi A, Sarvestani HJ. Comparing the static and dynamic balances and their relationship with the anthropometrical characteristics in the athletes of selected sports. Middle-East J Sci Res. 2013;15(2): 216-221; doi: 10.5829/idosi.mejsr.2013.15.2.7426.

12. Plisky PJ, Gorman PP, Butler RJ, Kiesel KB, Underwood FB, Elkins B. The reliability of an instrumented device for measuring components of the star excursion balance test. N Am J Sports Phys Ther. 2009;4(2): 92-99.

13. Bhat R, Moiz JA. Comparison of dynamic balance in collegiate field hockey and football players using star excursion balance test. Asian J Sports Med. 2013;4(3): 221-229.

14. International Society for the Advancement of Kinanthropometry (ISAK). International standards for anthropometric assessment. Underdale: ISAK; 2001.

15. Bartlett HL, Ting LH, Bingham JT. Accuracy of force and center of pressure measures of the Wii Balance Board. Gait Posture. 2014;39(1):224-228; doi: 10.1016/ j.gaitpost.2013.07.010.

16. Sgrò F, Monteleone G, Pavone M, Lipoma M. Validity analysis of Wii Balance Board versus baropodometer platform using an open custom integrated application. AASRI Procedia. 2014;8:22-29; doi: 10.1016/j. aasri.2014.08.005.

17. Clark RA, Bryant AL, Pua Y, McCrory P, Bennell K, Hunt M. Validity and reliability of the Nintendo Wii Balance Board for assessment of standing balance. Gait Posture. 2010;31(3):307-310; doi: 10.1016/j.gaitpost.2009.11.012.

18. National Health and Nutrition Examination Survey. Anthropometry procedures manual. 2004. Available from: https:/www.cdc.gov/nchs/data/nhanes/nhanes_ 03_04/bm.pdf.

19. Räty HP, Impivaara O, Karppi SL. Dynamic balance in former elite male athletes and in community control subjects. Scand J Med Sci Sports. 2002;12(2):111116; doi: 10.1034/j.1600-0838.2002.120208.x.

20. Vieira Tde M, de Oliveira LF, Nadal J. An overview of age-related changes in postural control during quiet standing tasks using classical and modern stabilometric descriptors.JElectromyogrKinesiol.2009;19(6):e513e519; doi: 10.1016/j.jelekin.2008.10.007.

21. Adegoke BOA, Babatunde FO, Oyeyemi AL. Pain, balance, self-reported function and physical function in individuals with knee osteoarthritis. Physiother Theory Pract. 2012;28(1):32-40; doi: 10.3109/09593985/2011. 570858. 


\section{HUMAN MOVEMENT}

F.O. Fasuyi, B.O.A. Adegoke, Physical characteristics and unipedal balance

22. Hue O, Simoneau M, Marcotte J, Berrigan F, Doré J, Marceau P, et al. Body weight is a strong predictor of postural stability. Gait Posture. 2007;26(1):32-38; doi: 10.1016/j.gaitpost.2006.07.005.

23. Alonso AC, Luna NMS, Mochizuki L, Barbieri F, Santos S, D’Andréia Greve JM. The influence of anthropometric factors on postural balance: the relationship between body composition and posturographic measurements in young adults. Clinics. 2012;67(12):14331441; doi: 10.6061/clinics/2012(12)14.

24. Greve J, Alonso A, Bordini ACPG, Camanho GL. Correlation between body mass index and postural balance. Clinics. 2007;62(6):717-720; doi: 10.1590/S1807 -59322007000600010. Available from: http:/www. scielo.br/pdf/clin/v62n6/08.pdf.

25. Berrigan F, Simoneau M, Tremblay A, Hue O, Teasdale N. Influence of obesity on accurate and rapid arm movement performed from a standing posture. Int J Obes. 2006;30(12):1750-1757; doi: 10. 1038/sj.ijo.0803342.

26. Friel K, McLean N, Myers C, Caceres M. Ipsilateral hip abductor weakness after inversion ankle sprain. J Athl Train. 2006;41(1):74-78.

27. Fabunmi AA, Gbiri CA. Relationship between balance performance in the elderly and some anthropometric variables. Afr J Med Med Sci. 2008;37(4):321-326.

28. Han J, Anson J, Waddington G, Adams R, Liu Y. The role of ankle proprioception for balance control in relation to sports performance and injury. Biomed Res Int. 2015;2015:842804; doi: 10.1155/2015/842804.

29. Pallant J. SPSS survival manual: a step by step guide to data analysis using IBM SPSS. Maidenhead: Open University Press; 2013. 